\title{
Conservadorismo condicional: estudo a partir de variáveis econômicas*
}

\section{Conditional conservatism: a study based on economic variables}

\author{
Rafael de Lacerda Moreira \\ Professor Assistente do Departamento de Ciências Contábeis do Centro de Ciências Jurídicas e Econômicas da Universidade Federal do Essírito \\ Santo*E-mail:moreiracco@yahoo.com.br \\ Romualdo Douglas Colauto \\ Professor Adjunto do Departamento de Contabilidade do Setor de Ciências Sociais Aplicadas da Universidade Federal do Paraná * E-mail: \\ rdcolauto@ufpr.br
}

Hudson Fernandes Amaral

Professor Associado do Centro de Pós-Graduação e Pesquisas em Administração do Departamento de Ciências Administrativas da Faculdade de Ciências Econômicas da Universidade Federal de Minas Gerais* E-mail: hfamaral@face.ufmg.br

Recebido em 06.04.2010 *.Aceito em 09.06.2010 * $2^{a}$ versão aceita em 17.11.2010

\section{RESUMO}

A Contabilidade, na perspectiva da abordagem da informação, volta-se à utilidade da informação. O Conservadorismo.Condicional está ligado à tendência de a Contabilidade exigir um maior grau de verificação das boas notícias para reconhecê-las no resultado em relação ao grau de verificação das más notícias. Em face das preocupações referentes à qualidade da informação contábil, o objetivo deste artigo consiste em analisar o reflexo do Conservadorismo Condicional no resultado contábil a partir de variáveis econômicas. O estudo utiliza o Modelo Reverso de Lucros Associados a Retornos (BASU, 1997) e o modelo proposto por Kahn e Watts (2009), que analisam a relação entre as variáveis lucro contábil e retorno econômico, utilizando os valores dos retornos positivos e negativos como proxy de boas e más notícias, e outras variáveis largamente aceitas na avaliação do conservadorismo. Para tanto, foram estimados os modelos estatísticos para uma amostra de 96 empresas para o período de 2005 a 2007 partindo de informações anuais disponíveis no Economática e dados reportados em notas explicativas. Com o objetivo de selecionar um evento econômico que pode impactar no reconhecimento assimétrico do resultado econômico, decidiu-se comparar os resultados entre empresas listadas nos níveis de governança da Bovespa com as demais empresas. Os resultados obtidos confirmam a hipótese de utilização de conservadorismo condicional na mensuração do resultado das companhias da amostra. A diferenciação positiva quanto ao grau de conservadorismo para as empresas que aderiram aos níveis de governança não são conclusivas, visțo que os modelos apresentaram resultados dispersos. As variáveis econômicas criam vantagens quando as más notícias não podem ser tão claramente visíveis nas Demonstrações Contábeis, podendo diminuir os resultados futuros esperados.

Palavras-chaves: Conservadorismo. Qualidade do lucro contábil. Accruals.

\section{ABSTRACT}

Accounting from an information perspective looks at the usefulness of that information. Conditional Conservatism is linked to the trend for accounting to require a higher degree of good news verification before disclosing it in the income when compared with the degree of bad news verification. In view of concerns with accounting information

* Artigo apresentado no $4^{\circ}$ Congresso ANPCONT, em Natal-RN, 2010. 
quality, this article aims to review the reflection of Conditional Conservatism in accounting income, based on economic variables. The study uses the Reverse Model of Associated Profit to Returns (BASU, 1997) and the model proposed by Kahn and Watts (2009), which examine the relation between accounting profit variables and economic return, using positive and negative returns as a proxy for good and bad news, and other variables widely accepted for the evaluation of conservatism. Therefore, statistical models were estimated for a sample of 96 companies from 2005 to 2007, based on annual information available in Economática and data reported in explanatory notes. To select an economic event that may influence the asymmetric recognition of economic income, the researchers decided to compare results between companies listed on Bovespa's governance levels and other companies. The obtained results confirm the hypothesis on the use of conditional conservatism among sample companies for income measurement purposes. The positive differences in the degree of conservatism for companies adhering to governance levels are not conclusive, as the models showed scattered results. The economic variables offer advantages when the bad news may not be as clearly visible in the financial statements, which may reduce expected future results.

Keywords: Conservatism. Accounting information quality. Accruals.

\section{INTRODUÇÃO}

Para Kothari (2001), o lucro contábil tem a função de demonstrar os resultados gerados pelas atividades operacionais e utilizados para uma aproximação da determinação dos fluxos futuros de caixa. Dado o interesse dos investidores, acionistas e credores em conhecer o valor da empresa, a capacidade informacional dos lucros deve transmitir para o usuário uma sinalização sobre o valor da empresa.

Uma das características do lucro é sua provável capacidade de predição. Os investidores podem estar interessados no lucro de hoje para a predição de lucros e dividendos futuros, assim como para predição do preço das ações. Sendo assim, "um dos aspectos cruciais da pesquisa sobre o impacto de lucros contábeis no mercado de capitais é a determinação do conteúdo informacional dos dados de lucro" (HENDRIKSEN; BREDA, 1999, p. 217).

A transparência da informação contábil é essencial para os usuários das informações financeiras. Contudo, as empresas podem ser estimuladas a não evidenciarem informações confiáveis, de tal modo que, para representar um bom desempenho financeiro e suprir os usuários externos, os gestores podem estar propensos a selecionar políticas contábeis mais conservadoras. Assim, os eventos econômicos influenciam na mensuração, reconhecimento e evidenciação do resultado contábil do período. Isso ocorre porque o lucro ou prejuízo contábil ajuda a atender à demanda dos usuários das informações contábeis, servindo como base para avaliar o desempenho da empresa.

Dessa forma, é necessário que haja uma maior atenção relacionada à qualidade da informação contábil, em especial, quando influenciado pela aplicação de práticas conservadoras. O Comitê de Pronunciamentos Contábeis (CPC, 2008) trata o Conservadorismo da forma em que os preparadores de demonstrações contábeis, ao se depararem com incertezas que inevitavelmente envolvem certas circunstâncias econômicas, devem divulgar sua natureza e extensão com o intuito de não criar expectativas que não sejam realizadas no futuro, tais como a possibilidade de recebimento de contas a receber de liquidação duvidosa e a vida útil provável das máquinas e equipamentos.

Essa é a forma Condicional do Conservadorismo, que consiste em precaução no exercício dos julgamentos necessários às estimativas em certas condições de incerteza, vinculadas a algum evento econômico, mas sem ferir a neutralidade dessas informações. Nesse sentido, a questão de pesquisa resumese em saber: como o resultado contábil de empresas brasileiras reflete a tendência de a Contabilidade reconhecer assimetricamente 
as perdas e ganhos decorrentes do Conservadorismo Condicional?

Nesse sentido, o objetivo do estudo consiste em analisar o reflexo do Conservadorismo Condicional no resultado contábil a partir de variáveis econômicas. O estudo está estruturado em quatro seções, além dessa introdu- ção. Inicialmente, apresenta-se a plataforma teórica sobre a qualidade da informação contábil. Após, mostram-se os procedimentos metodológicos e os modelos estatísticos utilizados. Na seção seguinte, são apresentados os resultados dos estudos e, por fim, as inferências conclusivas.

\section{QUALIDADE DA INFORMAÇÃO CONTÁBIL E CONSERVADORISMO CONDICIONAL}

A Contabilidade usa abstrações de eventos econômicos observados para mensurar, em forma de palavras e números, o resultado da empresa, porém, o objetivo da Contabilidade não se limita a apenas mensurar e sim o de transmitir compreensão desses eventos aos usuários. Segundo a American Accounting Associantion (Associação Americana de Contadores - AAA) (1966), a abordagem tradicional de comunicação de informação contábil exige um elevado grau de compreensão do processo de medição por parte do usuário. Esse processo é complexo e, quando combinado com a natureza técnica do material, coloca um peso significativo sobre o usuário. Para aliviar essa carga, a homogeneidade de significado das palavras e números utilizados na Contabilidade é essencial para facilitar a compreensão dos relatórios contábeis e aumentar sua utilidade.

De acordo com Anthony (1972) a Contabilidade tem sido denominada como linguagem dos negócios. Assemelha-se a uma linguagem quando algumas de suas regras são bem definidas e outras não. E ainda, quando há divergências de como um fato econômico deva ser registrado, semelhante à ausência de pleno consenso entre gramáticos quanto às estruturas de sentenças, pontuações e escolhas de palavras. Dias Filho (2000) entende que a função básica da Contabilidade é identificar, mensurar e comunicar informações destinadas a facilitar a tomada de decisões econômicas, visto que a compreensão dos códigos linguísticos usuais na Contabilidade é uma condição básica para que haja um bom aproveitamento das informações no processo decisório.

Shannon e Weaver (1963) explica que a Contabilidade pode ser analisada sobre a ótica da Teoria Matemática da Comunicação constituída pelos seguintes elementos: mensagem, emissor, canal, receptor e destinatário. A eficácia da linguagem contábil deve ser considerada na quantidade de informação assimilada e pelo volume de alternativas que ela permite ao usuário descartar. Para Dias Filho (2000), a informação reduz incertezas, assim, a validade da informação contábil pode ser determinada pela diferença do nível de incerteza do usuário antes e depois de receber a mensagem.

Para Jaedicke e Sprouse (1972, p. 25), o conhecimento do processo como a Contabilidade evidencia seus dados, cria uma consciência das limitações e dos poderes dos dados, bem como alertam quanto a possíveis melhorias. "É tão importante saber como determinado instrumento não pode ser usado quanto saber como pode". Ambos os conhecimentos são essênciais para a eficiência analítica da informação contábil.

Hendriksen e Breda (1999) definem as características qualitativas como as propriedades da informação que são necessárias para torná-la útil. A utilidade da Contabilidade como sistema de informação depende de sua capacidade de informar aos vários tipos de grupos de interesse associados à empresa.

A qualidade da informação contábil está direcionada a características que representam sua utilidade ante as demandas dos diversos 
tipos de usuário. Penman e Zhang (2002) são pragmáticos ao definir que a informação contábil será de boa qualidade quando representar um bom indicador do resultado futuro. Desse modo, as características qualitativas da informação contábil referem-se à evidenciação de resultados sustentáveis, isto é, as políticas contábeis de reconhecimento e mensuração devem evidenciar resultados que se realizarão no futuro próximo ou remoto.

Por fim, a confiabilidade é definida como a garantia que a informação está razoavelmente livre do erro e da polarização, e representa o que se propõe representar. Uma informação pode ser relevante, mas a tal ponto não confiável em sua natureza ou divulgação que o seu reconhecimento pode potencialmente distorcer as demonstrações contábeis (IASB, 2001). O CPC (2008) e IASB (2001) apontam cinco atributos presentes na informação confiável: (i) Representação adequada; (ii) Primazia da Essência sobre a Forma; (iii) Neutralidade; (iv) Integridade e (v) Prudência.

Para ser confiável, a informação deve representar, adequadamente, as transações e outros eventos que ela diz representar. Além disso, é necessário que essas transações e eventos sejam contabilizados e apresentados de acordo com a sua substância e realidade econômica (essência) e não meramente sua forma legal (forma). As informações devem ser neutras, não apresentando vieses que induziriam as decisões dos usuários, e contabilizadas na sua integridade, isto é, de forma completa.

A Prudência, também, denominada Conservadorismo, é definida como a prática contábil de antecipar perdas, mas nunca antecipar ganhos. Kam (1986) explica que os ativos e passivos são frequentemente avaliados num contexto de significativas incertezas, e a Contabilidade, portanto, respondeu por tomar uma atitude conservadora. Diante da incerteza dos valores, é preferível errar na subavaliação dos elementos positivos e sobreavaliação de itens negativos do que passar uma expectativa que pode não se realizar no futuro.

O Conservadorismo é, tradicionalmente, explicado pela tendência histórica e universal entre os contadores de seguir a regra informal de "não antecipar o registro de lucros, mas consignar antecipadamente todas as perdas" (BLISS, 1924 apud BASU, 1997, p. 7); o efeito da prática decorrente de tal máxima é de que os ativos tenderão a estar subavaliados e os passivos superavaliados por qualquer princípio contábil de mensuração que se aplique. Para Lopes (2001) o pior cenário deve ser considerado de forma a optar pela alternativa com maiores passivos e despesas ao mesmo tempo em que se escolhe a opção com menores ativos e receitas.

Feltham e Ohlson (1996) explicam esse tipo de conservadorismo como a persistente subavaliação do valor contábil do capital dos acionistas quando comparado com o valor de mercado da empresa. Estudos como o de Beaver e Ryan (2000) testaram a utilização desse tipo de conservadorismo com a diferença entre book-value e market-value.

Coelho (2007) adverte que simplesmente escolher menores valores para ativo e receitas e maiores valores para passivos e despesas, independente de verificação dos fatos econômicos não traz qualquer impacto informacional para os usuários da Contabilidade, o Conservadorismo não deve ferir a neutralidade das informações contábeis. Segundo García-Lara e Mora (2004) essa perspectiva de Conservadorismo se fundamenta de proteção, primeiramente, do capital de terceiros em contrapeso do capital dos acionistas.

Basu (1997) comenta, que sob a hipótese de motivações diferenciadas para entidades e gerentes, define Conservadorismo como a tendência dos contadores em exigir uma maior verificação para reconhecer perspectivas positivas (good news) que para registrar prováveis perdas (bad news). Por consequência, espera-se que os lucros publicados reflitam perdas econômicas mais tempestivamente que ganhos econômicos, devido à assimetria de tratamento dado à verificabilidade requerida para o registro antecipado dos dois tipos de fenômeno.

Ball e Shivakumar (2005) sugerem a ideia 
de Conservadorismo Condicional, referindose ao fenômeno que enfatiza a associação entre antecipação do registro e a possibilidade de perdas econômicas. Isso é diferente do Conservadorismo Incondicional que divulga baixos valores de Ativo e Receita independente de sinais de prováveis perdas econômicas. Coelho (2007) resume conceitualmente o Conservadorismo em:

(a) Incondicional: decorre da regra de que entre duas alternativas de mensuração e reconhecimento de eventos, igualmente válidas, deve-se escolher aquela que resulte na menor avaliação do patrimônio; motivado pelo grau de incerteza sobre os efeitos derivados de transações iniciadas;

(b) Condicional: refere-se à possibilidade de antecipar o reconhecimento contábil de perdas econômicas, ainda não realizadas, baseando-se em eventos atuais de cunho negativo, ou seja, reconhecer fatos econômicos de forma oportuna e assimétrica, privilegiando as más notícias ante as boas.

Grande contribuição foi dada por Khan e Watts (2009) que modificaram o modelo de Basu. Os referidos autores incluíram, no modelo, variáveis proxies amplamente aceitas para os fatores pautados às oportunidades de investimento e ao conservadorismo, que são o market-to-book, tamanho da empresa e alavancagem, desenvolvendo, assim, uma medida anual de conservadorismo para cada companhia.

Nesse ponto, a qualidade da informação perfaz um amplo conjunto de possibilidades de pesquisas na área contábil, nas quais se destacam a compreensibilidade das informações relatadas pela Contabilidade; o impacto dos resultados publicados nos preços das ações; gerenciamento de resultados contábeis e a utilização de Conservadorismo no reconhecimento contábil, foco deste trabalho. Observem-se alguns trabalhos que já aplicam os modelos de Basu (1997) e também de Ball e Shivakumar (2005), para análise do Conservadorismo em uma série de situações no mercado brasileiro. Por exemplo, Rangel e Teixeira (2003) estudaram o Conservado- rismo Incondicional encontrando evidências que o valor patrimonial das ações é maior do que o valor de mercado das empresas, concluindo que, na média, as empresas não são conservadoras.

Costa, Costa e Lopes (2006) constataram que o Conservadorismo está presente no processo de reconhecimento do retorno econômico pelo lucro contábil na Argentina, no Brasil, na Colômbia, no Peru e na Venezuela. No entanto, existe uma baixa relação entre o lucro e o retorno corrente, devido ao fato de que o principal foco da informação contábil nesses países, ainda, não ser o mercado de capitais.

Coelho e Lima (2007) pesquisaram se as sociedades por ação praticam o conservadorismo condicional na apuração dos lucros reportados nas demonstrações contábeis publicadas. Levantaram a hipótese de que a prática de conservadorismo não depende da existência de sinais de mau desempenho atual, implicando que os lucros publicados têm fraca eficiência informacional. Tal hipótese foi confirmada, visto que o atributo conservadorismo condicional não é encontrado nos resultados contábeis publicados.

Santos e Costa (2008) estudaram o nível de utilização do conservadorismo e a oportunidade do lucro nas demonstrações contábeis segundo as normas brasileiras e americanas nas companhias brasileiras que negociam ADRs. As evidências encontradas não confirmam as hipóteses de que exista um nível maior de utilização de conservadorismo por parte das normas americanas, nas empresas brasileiras emissoras de ADRs.

Gonzaga e Costa (2009) investigaram a existência de relação entre o nível de conservadorismo contábil e os conflitos sobre as políticas de dividendos entre acionistas controladores e minoritários sobre a política de dividendos. As evidencias oferecem indícios que exista relação entre as variáveis, porém os resultados não são conclusivos, visto que os resultados divergem entre as diferentes proxies utilizadas para conservadorismo.

Almeida, Scalzer e Costa (2008) utili- 
zaram o modelo de Basu (1997) para averiguar se o grau de conservadorismo utilizado pelas empresas que fazem parte dos níveis de governança da Bovespa diverge do grau de conservadorismo utilizado pelas demais empresas listadas na Bovespa. Os resultados apontaram maior utilização de conservadorismo pelas empresas listadas nos níveis de governança da Bovespa.

Todos esses estudos contribuíram para a discussão do tema qualidade informacional da contabilidade no Brasil, no entanto, existem vários pontos em que se pode avançar as discussões. Desse modo, a contribuição do presente trabalho consiste em analisar o conservadorismo nas empresas brasileiras considerando o modelo de Basu (1997) e o modelo proposto por Khan e Watts (2009). Além disso, investigar o impacto do conservadorismo no Lucro Líquido e no Lucro Operacional e a relação existente entre o conservadorismo e os níveis de governança da Bovespa.

\section{METODOLOGIA}

\subsection{Modelo reverso de lucros associados a retornos (BASU, 1997)}

O Modelo Reverso de Lucros Associados a Retornos, elaborado por Basu em 1997, permite investigar a relação entre as variáveis lucro contábil e retorno econômico. O autor estudou se, no período de 1963 a 1990, os retornos econômicos refletiam as más notícias (bad news) mais rapidamente que as boas notícias (good news). Analisou o reconhecimento assimétrico de boas e más notícias e como o lucro incorpora o retorno econômico. Para testar as hipóteses de oportunidade assimétri$\mathrm{ca}$, utilizou os valores dos retornos positivos e negativos como proxy de más e boas notícias.

O modelo utiliza a variabilidade dos retornos de mercado para explicar a variabilidade dos lucros contábeis, por isso a denominação "reverso". Utilizar o retorno das ações para explicar a variação no lucro pode parecer estranho, uma vez que se espera que o lucro divulgado cause efeito nos preços, como indicam as pesquisas de Ball e Brow (1968) que mostraram que os retornos são influenciados pelas informações contábeis. No entanto, Beaver (1968) descreve que os preços das ações parecem antecipar o comportamento do lucro devido a fontes mais rápidas do que a Contabilidade por utilizar um conjunto de informações disponíveis ao mercado que não necessariamente ainda está evidenciado na Contabilidade. Ohlson (2001) exemplifica que as previsões de analistas constituem uma ferramenta razoável para mensurar os lucros esperados, o que justifica o emprego do modelo reverso de lucros associados a retornos. O Modelo Reverso de Lucros Associados a Retornos é expresso na Equação 1.

$$
\begin{aligned}
\frac{L u c_{i t}}{P_{i t-1}} & =\beta_{0}+\beta_{1} D_{i t}+\beta_{2} \frac{R E_{i t}}{P_{i t-1}} \\
& +\beta_{3} D_{i t} * \frac{R E_{i t}}{P_{i t-1}}+\varepsilon_{i t}
\end{aligned}
$$

em que:

$L u c_{i t}=$ Lucro líquido (contábil) por ação da empresa $i$ no ano $t$;

$P_{i t-1}=$ Preço da ação da empresa $i$ no final do ano anterior;

$B_{0}=$ Termo de intercepto;

$D_{i t}=\quad$ Variável dummy, será 1 se o retorno econômico for negativo e 0 se o retorno econômico for positivo ou nulo;

$B_{2}=$ Reflete a oportunidade do lucro contábil, isto é, o reconhecimento do retorno econômico pelo lucro contábil;

$\beta_{1} e \beta_{3}=$ Refletem o reconhecimento assimétrico do retorno econômico às boas e más notícias, pelo lucro contábil;

$R E_{i t}=$ Retorno econômico por ação da empresa $i$ no ano $t$ (Pit - Pit-1 ajustado pelo pagamento de dividendos);

$\varepsilon_{i t}=\quad$ Termo de erro da regressão.

A variável dummy é utilizada para verificar se o lucro contábil é mais sensível aos 
resultados negativos que aos positivos. $\mathrm{O}$ coeficiente $\beta_{2}$ reflete o reconhecimento do retorno econômico pelo lucro. Os parâmetros da regressão $\beta_{1}$ e $\beta_{3}$ são definidos como os coeficientes que refletem o reconhecimento assimétrico do retorno econômico pelo lucro contábil. Assim, os coeficientes $\beta_{1}$ e $\beta_{3}$ podem refletir as práticas conservadoras. Portanto, o modelo assume que as más notícias capturadas pelo mercado são derivadas do Conservadorismo contábil adotado pelas empresas. $\mathrm{O}$ coeficiente $\beta_{0}$ não contém significado econômico/teórico, porque ele não está relacionado a nenhuma questão de boas e más notícias, a sua utilização é inerente ao próprio modelo estatístico.

Os coeficientes $\beta_{1}$ e $\beta_{3}$ ao capturarem o reconhecimento assimétrico entre boas e más notícias apresentarão sinal negativo para $\beta_{1} \mathrm{e}$ positivo para $\beta_{3}$. O parâmetro $\beta_{1}$ mensura a diferença entre reconhecimento contábil de boas e más notícias já absorvidas pelo preço de mercado. $O$ coeficiente $\beta_{3}$ mensura a intensidade desse reconhecimento entre de boas e más notícias.

Para controle da heterocedasticidade, Basu (1997) divide as variáveis contábeis $L u c_{i t}$ e $R E_{i t}$ pelo preço da ação do final do ano anterior $\left(P_{i t-1}\right)$ diminuindo possíveis problemas estatísticos referentes a características de cada empresa da amostra. Com isso, o retorno do período é demonstrado em escala percentual em relação ao período passado e o lucro passa a ser medido em relação ao preço da ação do período anterior, uma espécie de medida de retorno.

Neste trabalho, o modelo aplicado utilizam-se os seguintes agregados para o resultado contábil: (a) Lucro Líquido e (b) Lucro Operacional. De acordo com Coelho (2007), a análise desses diversos agregados tem o propósito de mensurar efeitos específicos das rubricas contábeis, como questões tributárias e itens não operacionais.

$\mathrm{O}$ agregado Lucro Líquido possibilita a análise da influência do Conservadorismo em todas as contas que passam pela Demonstração do Resultado do Exercício (DRE) in- clusive nas contas que não são operacionais e as rubricas após a incidência do Imposto de Renda e Contribuição Social Sobre o Lucro. Ao comparar os achados da pesquisa empírica, decorrentes da utilização do Lucro Líquido e Lucro Operacional, haverá possibilidade de inferir sobre o impacto de itens não operacionais e dos impostos incidentes sobre o resultado operacional próprios do Lucro ou Prejuízo do período apurado de acordo com o Regime de Competência. Esse pressuposto é previsto em Watts (2003) que afirma que a tributação tem forte influência sobre as práticas Conservadoras, na medida em que as empresas lucrativas podem reduzir desembolsos tributários por meio da postergação das receitas e aceleração das despesas.

Assaf Neto (2008) explica que, em finanças, a avaliação de desempenho operacional é denominada lucratividade, e tem por base a determinação do lucro operacional da empresa, refletindo o efetivo valor gerado por seus ativos. A lucratividade é formada pelas operações da empresa, independentemente da maneira como essas operações se encontram financiadas. Em outras palavras, é o resultado da empresa oriundo dos esforços desenvolvidos para cumprimento de seu objetivo social. O lucro líquido é o resultado do acionista, dependente dos ativos e passivos, mas relacionado com o capital de propriedade dos acionistas, refletindo a rentabilidade auferida.

\subsection{Modelo proposto por Khan e Watts (2009)}

Khan e Watts (2009) alteraram o modelo de Basu (1997) encontranto uma métrica anual de conservadorismo para cada empresa. Incluíram variáveis proxies largamente aceitas para os fatores pautados às oportunidades de investimento e para avaliação do conservadorismo.

As variáveis são:

a) Índice Market to Book $(M / B)$ : compara os valores de mercado e patrimonial de ações no final exercício;

b) Tamanho: constituído pelo Log Natural 
do valor de mercado da ação e

c) Alavancagem: representada pelo exigível dividido pelo valor de mercado do patrimônio.

A motivação para a consideração do $\mathrm{M} / \mathrm{B}$ dá-se , conforme Khan e Watts (2009), pelo fato que empresas com alto índice $\mathrm{M} / \mathrm{B}$ estão associadas com maiores opções de crescimento em relação aos ativos investidos, e as opções de crescimento são positivamente relacionadas com o custo de agência. Nesse aspecto, o conservadorismo é uma eficiente resposta de governança corporativa ao custo de agencia (WATTS, 2003) e, por consequência, há relação entre $\mathrm{M} / \mathrm{B}$ e conservadorismo.

Givoly e Hayn (2000) utilizaram o marketto-book como proxy para aferir Conservadorismo Incondicional, assumindo que esse índice seria sempre maior que um, caso práticas conservadoras fossem utilizadas. Dito de outra forma, quando essa relação é maior que um, o mercado está reconhecendo que determinada empresa vale mais do que está registrado nos seus livros, possivelmente por práticas de conservadorismo incondicional.

Khan e Watts (2009) comentam que essa subavaliação feita pela contabilidade é reforçada pela contabilização imediata de gastos feitos, em que não é possível apresentar certo grau de confiabilidade de retornos futuros, como, por exemplo, gastos com pesquisa e desenvolvimento ou a mensuração de certos intangíveis.

O tamanho da empresa como variável é motivado pelo fato de que as maiores corporações possuem maior evidência e divulgação de informações, o que implicaria menor assimetria de informação (EASLEY; HVIDKJAER; O'HARA, 2002). Considera-se a alavancagem, visto que as corporações mais endividadas, ou alavancadas, possuem maiores conflitos de agência (WATTS, 2003a) e, dessa forma, são positivamente relacionadas com o conservadorismo e, consequentemente, com a assimetria de informação.

Para a elaboração do seu modelo, Khan e Watts (2009) partiram do corte transversal do modelo de Basu (1997), conforme Equação 2 .
$X_{i}=\beta_{0}+\beta_{1} D+\beta_{2} R E_{i}+\beta_{3} D_{i t}^{*} R E_{i}+\varepsilon_{i t}$

em que:

$X_{i}=\quad$ Lucro (contábil) por ação da empresa i dividido pelo Preço da Ação do período anterior;

$\beta_{0}=$ Termo de intercepto;

$D_{i}=\quad$ Variável dummy, será 1 se o retorno econômico for negativo e 0 se o retorno econômico for positivo ou nulo;

$\beta_{2}=$ Reflete a oportunidade do lucro contábil, isto é, o reconhecimento do retorno econômico pelo lucro contábil;

$\beta_{1} e \beta_{3}=$ Refletem o reconhecimento assimétrico do retorno econômico às boas e más notícias, pelo lucro contábil;

$R E_{i}=$ Retorno econômico por ação da empresa $i$ no ano $t$ (Pit - Pit-1 ajustado pelo pagamento de dividendos) dividido pelo preço da ação do período anterior;

$\varepsilon_{i}=\quad$ Termo de erro da regressão.

Após, os autores estabeleceram que o estimador de boas notícias G_Score seria obtido pela Equação 3 e o de más notícias C_Score pela Equação 4, resultando então, o modelo anual de regressão de corte transversal, conforme Equação 5, sendo que esse inclui variáveis de controle para as principais características das corporações e pode ser considerado, também, como de equações simultâneas e com a utilização de variáveis dummies de coeficiente angular.

$$
\begin{aligned}
& G_{-} \text {Score }=\beta_{3}=\mu_{0}+\mu_{1} \operatorname{Tam}_{i}+\mu_{2} \text { MB }_{i}+\mu_{3} \text { Alav }_{i} \\
& \text { C_Score }=\beta_{4}=\lambda_{0}+\lambda_{1} \text { Tam }_{i}+\lambda_{2} M B_{i}+\lambda_{3} \text { Alav }_{i} \\
& X_{i}=\beta_{0}+\beta_{1} D_{i}+R E_{i}\left(\mu_{0}+\mu_{1} \operatorname{Tam}_{i}\right. \\
& \left.+\mu_{2} M B_{i}+\mu_{3} \text { Alav }_{i}\right)+ \\
& +D_{i t} * R E_{i}\left(\lambda_{0}+\lambda_{1} \operatorname{Tam}_{i}+\lambda_{2} M B_{i}+\right. \\
& \left.+\lambda_{3} \text { Alav }_{i}\right)+\varepsilon_{i t}
\end{aligned}
$$

A hipótese do modelo é a de que os índices $\mathrm{M} / \mathrm{B}$ e a alavancagem são positiva e significativamente associados à relação lucro/ 
preço defasado, enquanto o tamanho é, negativa e significativamente, associado à variável dependente. Diferentemente do modelo de Basu (1997), a métrica é calculada por empresa/ano, desse modo, as estatísticas foram estimadas utilizando cross-section dos anos de 2005, 2006 e 2007.

\subsection{Definição da amostra}

No final de 2000, a Bolsa de Valores de São Paulo (Bovespa) criou listagens específicas (Novo Mercado e Governança Corporativa Nível 1 e Nível 2) para empresas que, voluntariamente, aderissem a compromissos de respeito aos acionistas minoritários e de transparência na divulgação das informações da companhia.

Para analisar a qualidade da informação contábil numa perspectiva de utilidade da informação foram inicialmente, consideradas todas as companhias de capital aberto que negociam suas ações na Bovespa. Dessa população, foram, prontamente, excluídas as companhias do setor financeiro, as prestadoras de serviços vinculadas à internet, uma vez que é notório que características de estrutura de capital, características operacionais e de investimentos, bem como toda a estrutura contábil não é análoga às demais empresas.

A coleta de dados secundários foi realizada a partir do banco de dados Economática, no qual foi possível acessar os relatórios contábeis das companhias e as informações referentes ao desempenho em termos de oscilação dos preços das ações. Utilizaram-se demonstrações contábeis anuais para o período de 2005 a 2007. Sempre que possível, foram utilizadas as demonstrações consolidadas.

O lucro líquido por ação foi coletado no Economática já ponderado pelos desdobramentos de ações efetuados pelas companhias. A partir desse valor ponderado do lucro líquido e dos valores absolutos de lucro líquido e lucro operacional, calculou-se o lucro operacional por ação.

Um aspecto muito importante encontrado foi a inexistência de informações de diversos itens (lacunas) da base de dados no sistema. Para que a amostra não fosse intensamente reduzida, recorreu-se a outras fontes de dados para preenchimento dessas lacunas. Para as empresas do setor energético, alguns dados foram encontrados no anuário Séries dos anos de 2006 e 2007, elaborado pelo Grupo de Estudos do Setor de Energia Elétrica (GESEL) da UFRJ. Por último, foi feita uma análise de todo o conteúdo reportado nas notas explicativas das empresas em que ainda existiam lacunas quanto a alguma informação necessária.

A baixa liquidez dos papeis de muitas empresas não possibilitando a utilização do preço de suas ações e o cálculo do retorno econômico mostrou-se como grande limitador de pesquisa. Considerando o exposto, a amostra foi composta por 96 empresas. Para analisar os resultados na ótica relação entre nível de governança da Bovespa e qualidade da informação contábil publicada, a amostra final de 96 empresas foi subdividia em dois novos subgrupos. O primeiro grupo formado por 58 empresas que optaram por alguns dos três níveis de governança da Bovespa e o segundo grupo por 38 empresas que não fizeram a opção por participação dos níveis da Bovespa.

\subsection{Janela de eventos}

Campbell, Lo e MacKinlay (1997) informam que, para estudar o impacto de determinadas informações divulgadas ao mercado de capitais e aferir a eficiência de mercado, é necessário definir o evento de interesse e também identificar a sua data de ocorrência, ou seja, a data "zero". Para essa pesquisa, ficou estabelecido como data "zero" o dia em que as empresas divulgaram suas demonstrações financeiras. Sugerem, também, estabelecer uma janela em que será testado se houve impactos ou não nos retornos das ações. Por apresentar certo grau de subjetividade, tal janela não deve ser muito ampla, a fim de que o envolvimento de outros eventos que não o observado seja evitado, também não deve ser estreita, sob o risco de não captar as anorma- 
lidades que se espera observar.

Para o emprego das variáveis econômicas: retorno das ações $\left(\mathrm{RE}_{\mathrm{it}}\right)$ e Preço das ações de períodos anteriores $\left(\mathrm{P}_{\mathrm{it}-1}\right.$ e $\left.\mathrm{P}_{\mathrm{it}-2}\right)$, optou-se por uma janela composta pelos dados da $\mathrm{BO}$ VESPA referentes à média das cotações das ações nos cinco dias posteriores ao evento (divulgação das demonstrações financeiras). Essa janela de cinco dias foi utilizada com a intenção de cientificar que o mercado assimila as informações contábeis publicadas oportunamente.

Pesquisas semelhantes (ANTUNES; PROCIANOY, 2003; TAKAMATSU; LAMOUNIER; COLAUTO, 2008) utilizaram uma janela de cinco dias após a divulgação das informações financeiras pelas companhias para assegurar a resposta do mercado. Antunes e Procianoy (2003) investigaram como o preço das ações é influenciado por decisões de investimento em ativos. Takamatsu, Lamounier e Colauto (2008) analisaram os impactos da divulgação de prejuízos nos retornos de ações de companhias participantes do Bovespa. No entanto, para as ações com menor liquidez, caso não apresentassem negociações no prazo de 5 dias após a publicação das demonstrações, aceitou-se a utilização de valores com o prazo de até 30 dias.

Em virtude do exposto anteriormente, assume-se a hipótese de que os mercados são eficientes na sua forma semiforte, conforme estudos realizados por Perobelli, Perobelli e Arbex (2000), que inferem que o mercado brasileiro reflete, pronta e corretamente, as informações relevantes disponíveis ao público externo. A hipótese de eficiência de mercados é tratada, inicialmente, por Famá (1970) e pode assumir as seguintes formas: (i) fraca; (ii) semiforte e (iii) forte. O mercado é eficiente na sua forma fraca quando reflete apenas o comportamento histórico dos preços. Semiforte, quando, além do comportamento histórico, reflete informações disponíveis publicamente, desde que relevantes, como as informações contábeis. Finalmente, na forma forte quando esse incorporar informações privadas obtidas pelos agentes.
3.4 Abordagens dos dados em painel

Os modelos estatísticos deste trabalho foram estimados utilizando o Software Stata versão 10.0. O modelo original de Basu (1997) utiliza a abordagem de estimação por dados em painel, que, segundo Maddala (2003), se refere aos conjuntos de informações sobre o mesmo indivíduo ao longo de vários períodos de tempo.

Conforme Hsiao (1986), a análise de dados em painel em comparação com modelos de corte transversal ou aos de séries temporais, apresenta vantagens como o controle de alguns problemas estatísticos como heterogeneidade dos dados de diferentes indivíduos, aumentam o número de graus de liberdade e diminui a colinearidade entre as variáveis explanatórias.

Outras vantagens da análise de dados em painel são mencionadas por Gujarati (2006): proporcionar dados mais informativos e medição mais adequada para estudos em que a amostra passou por mudanças consideráveis, como crises econômicas, por mudanças estratégicas ou até mesmo mudança de valores e práticas predominantes no processo decisório em diferentes níveis organizacionais, uma vez que não concentra a análise sobre uma empresa em particular ou sobre um período específico. A análise de painel nas abordagens mais comuns são: Polled OLS, Efeitos Fixos e Efeito Aleatório. Um modelo geral de painel balanceado, de T observações para $\mathrm{N}$ indivíduos, pode ser representado pela Equação 6:

$$
\begin{aligned}
& Y_{i t}=\alpha_{0 i t}+\alpha_{1 i t} X_{i t}+\varepsilon_{i t} \\
& i=1, \ldots, N \quad t=1, \ldots T
\end{aligned}
$$

\subsubsection{Determinação da escolha da abordagem de painel}

Para a determinação da melhor abordagem para a estimação dos modelos, serão feitos os testes específicos, uma vez que não se conhece, a priori, o comportamento dos dados existentes para as empresas. De acordo com a sugestão de Silva e Cruz Jr. (2004) serão realizadas três etapas de testes: (1) Com- 
paração entre Polled (modelo restrito) e Efeitos Fixos (EF); (2) Comparação entre Polled (modelo restrito) e Efeitos Aleatórios (EA) e (3) Comparação entre Efeitos Fixos (EF) e Efeitos Aleatórios (EA).

- Comparação entre Polled (modelo restrito) e Efeitos Fixos (EF)

Teste: Chow

Hipótese nula: interceptos comuns (Modelo Restrito)

Hipótese alternativa: interceptos diferentes para cada seção cruzada (EF)

- Comparação entre Polled (modelo restrito) e Efeitos Aleatórios (EA)

Teste: LM-Breusch-Pagan

Hipótese nula: interceptos comuns (Modelo Restrito)

Hipótese alternativa: interceptos diferentes para cada seção cruzada (EF)

- Comparação entre Efeitos Fixos (EF) e Efeitos Aleatórios (EA)

Teste: Hausman

Hipótese nula: resíduos não correlacionados com variável explicativa (EF)

Hipótese alternativa: resíduos correlacionados com variável explicativa (EA)

\subsection{Estimação das médias das cross-sections conforme Fama e McBeth (2009)}

O modelo de Kahn e Watts (2009), neste artigo, foi estimado levando em consideração o trabalho realizado por Fama e McBeth (1973), que sugere uma forma alternativa para estimação de regressões cross-section assim como para cálculo dos desvios-padrão e estatísticas de teste. De acordo com Lima e Brito (2010), esse processo é bastante utilizado em estudos na área de finanças corporativas sendo historicamente um procedimento importante e de fácil implementação.

O primeiro passo do procedimento de Fama e McBeth (1973) é rodar regressões cross-section para cada período de tempo $\mathrm{t}$. Assim, foram rodadas as regressões para os anos de 2005, 2006 e 2007. Utilizando a série, estimou-se sua média, conforme Equa- ção 7 e inferiu-se sua variância, Equação 8, utilizando os desvios dos estimadores com relação à média.

$$
\bar{\beta}=\frac{1}{T} \sum_{t=1}^{T} \hat{\beta}_{t}
$$

$$
\sigma^{2}(\hat{\beta})=\frac{1}{T^{2}} \sum_{t=1}^{T}(\hat{\beta} t-\bar{\beta})^{2}
$$

A partir dos cálculos das estatísticas, pode-se definir a estatística de teste $t$ de Student a fim de testar a significância dos resultados, conforme Equação 9, e compará-la ao t tabelado ao nível de $10 \%$, que, neste estudo, é igual a 1,6688 . Desse modo, todos os valores da estatística t para os coeficientes que apresentarem resultados maiores que 1,6688 são considerados significativos e possibilitam inferências.

$t_{\beta}=\frac{\bar{\beta}}{\sigma(\hat{\beta})}$

A principal vantagem da estimação por Fama e McBeth (1973) é o de corrigir os dados para a correlação seccional, produzindo, assim, melhores resultados com uma significativa redução dos desvios da média. Além dessa correção, esse procedimento apresenta robustez com respeito à heterocedasticidade visto que não existe correção para a heterocedasticidade dos dados para uma amostra de médias. Já o problema de autocorrelação é resolvido ajustando a estatística de teste requerida.

Cochrane (2001) demonstra que, quando a variável independente não varia no tempo, o procedimento de Fama e McBeth (1973) é equivalente, numericamente, à estimação via painel e cross-section simples com correção para a autocorrelação, porém, quando ocorre uma variação temporal na variável independente, existem diferenças significativas entre esses três métodos de estimação, em que o resultado por Fama e McBeth (1973) é o que apresenta maior robustez. 


\subsection{Testes para a análise de relaxamento dos pressupostos básicos de regressão linear}

Antes de realizar os testes para a escolha de qual abordagem seria utilizada para estimar as regressões em painel, foram realizados testes de relaxamento dos pressupostos básicos de regressão linear. A análise de regressão baseia-se na hipótese de que os erros seguem uma distribuição normal. A condição de normalidade dos resíduos não é necessária para a obtenção dos estimadores de mínimos quadrados, mas é fundamental para a definição de intervalos de confiança e testes de significância, ou seja, em presença de falta de normalidade, os estimadores são não tendenciosos, mas os testes não têm validade, principalmente em amostras pequenas. Assincronicamente, a estatística de Jarque-Bera segue a distribuição qui-quadrado com 2 graus de liberdade. Neste trabalho, considerou-se uma probabilidade de até $10 \%$ para não rejeitar a hipótese de normalidade dos resíduos.

Para testar se as regressões estimadas são heterocedásticas foi utilizado o teste geral de heterocedasticidade de White. Segundo Gujarati (2006) o teste de White não depende da premissa de normalidade e, devido a sua fácil implementação, é o mais comumente utilizado em trabalhos acadêmicos. O teste de White é conduzido a partir dos resíduos da regressão auxiliar estimada $\left(\varepsilon_{i t}\right)$.

Ainda, pode existir o problema da autocorrelação dos resíduos, isto é, o método clássico pressupõe que o termo de erro relacionado a qualquer das observações não é influenciado pelo termo de erro de qualquer outra observação. A ausência de autocorrelação nos resíduos foi examinada pela estatística 'd' de Durbin e Watson em níveis de significância de 0,05.

Sabendo que a autocorrelação causa falta de eficiência dos estimadores de MQO, uma vez encontrado o problema pelo teste de Durbin Watson, foi efetuado a correção a partir do método dos Mínimos Quadrados Generalizados (MQG). Em caráter ilustrativo, vejase um modelo de duas variáveis conforme a Equação 10, supondo que o termo de erro segue o esquema autorregressivo de primeira ordem AR (1), conforme a Equação 11.

$Y_{i t}=\beta_{0}+\beta_{1} X_{i t}+u_{i t}$

$u_{i t}=\rho u_{i t-1}+e_{i t} \quad-1<\rho<1$

Optou-se por estimar rô $(\rho)$ a partir da regressão dos resíduos $\hat{u}_{t}$ contra $\hat{u}_{t-1}$, haja vista que os $\hat{u}_{t}$ são estimadores consistentes do verdadeiro $\hat{u}_{t}$, calcula-se a Equação 12 .

$\hat{u}_{i t}=\rho \cdot \hat{u}_{i t-1}+v_{i t}$

Em que $\hat{u}_{t}$ são os resíduos obtidos na regressão original e $v_{t}$ são os termos de erro dessa regressão. Não há necessidade de incluir o termo de intercepto, pois a soma dos resíduos dos MQO é igual a zero. Assim, a estimativa de $\rho$ é utilizada para transformar as variáveis a fim de estimar a equação de diferenças generalizadas.

\section{ANÁLISE DOS RESULTADOS}

\subsection{Análise das estatísticas descritivas para o Modelo de Basu (1997)}

Na Tabela 10 , são apresentadas as estatísticas descritivas das 96 companhias que compuseram a amostra. Nas regressões, foi utilizado painel balanceado em um total de 288 observações. O objetivo dessa análise é infe- rir sobre as principais medidas de tendência central e dispersão quanto à situação de seus resultados líquido e operacional, preços das ações e sobre a variação do preço das ações, nesse modelo chamado de retorno econômico. Na parte "A" da Tabela, são demonstradas as variáveis em seus valores absolutos e, na Parte "B", seus valores divididos pelo preço 
da ação do período anterior, conforme sua utilização no modelo de regressão estatística. A estatística descritiva da parte A da Tabela é calculada a partir do Lucro Líquido por ação e Lucro Operacional por ação dos anos de 2005 a 2007. Considerando que, para a modelagem estatística, foram utilizados os lucros divididos pelo preço da ação do período anterior, apresentam-se as estatísticas descritivas dos preços das ações com base nos anos de 2004 a 2006.

Em valores absolutos, as empresas da amostra apresentam valores médios para Lucro Líquido e Lucro Operacional positivos. A mediana dessas variáveis também é positiva, porém com valores menores do que a média. Ordenados os elementos da amostra, a mediana é o valor que a divide ao meio, isto é, $50 \%$ dos elementos da amostra são menores ou iguais à mediana e os outros $50 \%$ são maiores.

Essa diferença pode ser explicada pelo fato de algumas companhias apresentarem lucratividade e rentabilidade consideravel- mente maior que as demais empresas da amostra, como, por exemplo, a Vale S.A que apresentou Lucro Líquido por ação de R\$ 11,66 e R\$ 17,37 nos anos de 2006 e 2007 respectivamente, ou a Companhia Energética de Brasília com R $\$ 13,10$ e a Telemar Norte Leste S.A com R\$ 11,28 em 2007. Verifica-se elevado desvio-padrão do preço das ações bem como do lucro líquido e operacional, o qual fornece algumas informações relevantes sobre a realidade brasileira. A diferença nos preços das ações de algumas empresas é considerável e as estatísticas apresentam diferenças entre mínimo e máximo superior a $\mathrm{R} \$$ 130,00. Como medida de localização, a mediana é mais robusta do que a média, pois não é tão sensível às observações quando muito maiores ou muito menores que as restantes, por outro lado, a média reflete o valor de todas as observações.

Nas variáveis da Parte "B”, observa-se que a média dos lucros líquido e operacional, também, é positiva e maior que a mediana. Outra observação interessante diante dos

Tabela 1 Estatísticas descritivas para o modelo reverso de lucros associados a retornos

\begin{tabular}{|c|c|c|c|c|c|c|c|}
\hline Variáveis & Obs & Média & Mediana & $\begin{array}{l}\text { Desvio } \\
\text { Padrão } \\
\end{array}$ & Assimet. & Min & Máx \\
\hline \multicolumn{8}{|c|}{ Parte "A" - valores absolutos } \\
\hline $\begin{array}{l}\text { Lucro } \\
\text { Líquido } \\
\text { por ação }\end{array}$ & 288 & 1,6075 & 0,9363 & 2,9228 & 0,3252 & $-16,7901$ & 17,3732 \\
\hline $\begin{array}{l}\text { Lucro } \\
\text { Operacional } \\
\text { por ação }\end{array}$ & 288 & 2,2337 & 1,0989 & 3,9784 & 0,2923 & $-20,3546$ & 23,6101 \\
\hline $\begin{array}{l}\text { Preço } \\
\text { da ação }\end{array}$ & 288 & 16,3280 & 12,9254 & 14,9671 & 2,3172 & 0,0082 & 114,8757 \\
\hline \multicolumn{8}{|c|}{ Parte "B" - Valores divididos pelo preço da ação do período anterior } \\
\hline $\begin{array}{l}\text { Lucro } \\
\text { Líquido } \\
\text { por ação }\end{array}$ & 288 & 0,1011 & 0,0995 & 0,1782 & $-1,5526$ & $-1,1579$ & 0,6440 \\
\hline $\begin{array}{l}\text { Lucro } \\
\text { Operacional } \\
\text { por ação }\end{array}$ & 288 & 0,1505 & 0,0143 & 0,2432 & $-0,5990$ & $-1,4038$ & 0,9246 \\
\hline $\begin{array}{l}\text { Retorno } \\
\text { Econômico }\end{array}$ & 288 & 0,4309 & 0,2876 & 0,7764 & 5,2623 & $-0,6245$ & 8,5580 \\
\hline
\end{tabular}


dados obtidos das empresas é que o desviopadrão do Lucro Líquido é, percentualmente, maior do que o do Lucro Operacional em relação à média, $176 \%$ e $162 \%$ respectivamente, o que demonstra maior homogeneidade nas receitas e custos e despesas operacionais.

A estatística descritiva do retorno econômico mostra que, em média, há aumento no preço das ações equivalente a $43 \%$ por período para as empresas amostradas. Mais uma vez, a mediana foi menor que a média, demonstrando assimetria positiva na distribuição dos valores de retorno econômico de mais de 500\%. Conforme Maroco (2003), a assimetria de uma distribuição é caracterizada pelo enviesamento que essa distribuição apresenta relativamente à média. Quando a distribuição se concentra do lado direito com uma cauda do lado esquerdo, o valor de assimetria é menor que zero e diz-se que a distribuição apresenta enviesamento negativo ou assimétrica à esquerda. Caso contrário, se a distribuição se concentrar do lado esquerdo, o índice de assimetria toma sinal positivo e a distribuição diz-se com enviesamento positivo ou assimétrica à direita.

Os valores de média, mediana e assimetria negativa encontrada para o lucro são um indicativo de intencionalidade dos administradores em reportar resultados líquidos próximos de $R \$ 0,10$ por ação. A estatística descritiva, no entanto, não possibilita inferências sobre que natureza se baseia essa intencionalidade, podendo ser conservadorismo ou prática de gerenciamento de resultados. Desse modo, as variáveis foram estimadas em regressão, possibilitando descrever relações de causa e efeito entre elas.

\subsection{Análise da regressão reversa de lucros associados a retornos (Basu 1997)}

Na Tabela $2 \mathbf{0}$, apresentam-se os resultados das regressões estatísticas, conforme o modelo de Basu (1997) para análise do Conservadorismo na mensuração contábil, medido pelo reconhecimento assimétrico de boas e más notícias a respeito do retorno econômico sob a cotação das ações. Tais efeitos foram examinados em dois diferentes conceitos de lucro: Lucro Líquido e Lucro Operacional, o que possibilita inferir sobre as diferenças de reconhecimento discricionário dos accruals em aspectos voltados para rentabilidade e lucratividade operacional das empresas.

$\mathrm{Na}$ estimação dos coeficientes para o modelo foi empregada a abordagem de efeitos fixos. A estimação para o Lucro Líquido não apresentou problemas relacionados a relaxamento dos pressupostos estatísticos de Método de Mínimos Quadrados (MQO). No entanto, a estimação para Lucro Operacional apresentou autocorrelação dos resíduos, conforme teste de Durbin Watson. Para correção a desse problema, a regressão foi reestimada utilizando-se Mínimos Quadrados Generalizados com distúrbios correlacionados considerando como forma de correlação Panel-

Tabela 2 Resultado da regressão reversa de lucros associados a retornos

\begin{tabular}{|c|c|c|c|c|c|c|}
\hline \multirow{2}{*}{ Coeficientes } & \multicolumn{3}{|c|}{ Lucro Líquido } & \multicolumn{3}{|c|}{ Lucro Operacional } \\
\hline & Valor & Teste $\mathrm{t}$ & Prob. & Valor & Teste $\mathrm{z}$ & Prob. \\
\hline$\beta_{0}$ & 0,10 & 7,83 & 0,00 & $0,14^{*}$ & $9,37^{*}$ & $0,00^{*}$ \\
\hline$\beta_{1}$ & $-0,03$ & $-0,78$ & 0,43 & $-0,02^{*}$ & $-0,48^{*}$ & $0,63^{*}$ \\
\hline$\beta_{2}$ & 0,01 & 1,07 & 0,26 & $0,03^{*}$ & $1,63^{*}$ & $0,01^{*}$ \\
\hline$\beta_{3}$ & 0,03 & 0,24 & 0,81 & $0,26^{*}$ & $1,04^{*}$ & $0,10^{*}$ \\
\hline $\mathrm{R}^{2}$ ajustado & \multicolumn{3}{|c|}{$3,33 \%$} & \multicolumn{3}{|c|}{-} \\
\hline $\mathrm{N}$ & \multicolumn{3}{|c|}{96} & \multicolumn{3}{|c|}{96} \\
\hline $\mathrm{T}$ & \multicolumn{3}{|c|}{3} & \multicolumn{3}{|c|}{3} \\
\hline
\end{tabular}

* Valores reestimados pelo MQG do software estatístico Stata 
specific AR (1) e autocorrelação dos resíduos como método de computação do software.

O coeficiente de interseção $\beta_{0}$ mostrou-se significativo ao nível de $1 \%$ e com maior valor para o Lucro Operacional em relação ao Lucro Líquido, porém a interpretação desse coeficiente não faz sentido no aspecto da detecção de utilização e as conseqüências do Conservadorismo na mensuração do resultado das companhias.

Os coeficientes que medem o conservadorismo, apesar de não serem estatisticamente significantes para o Lucro Líquido $\left(\beta_{1}\right.$ e $\beta_{3}$ ) e Lucro Operacional $\left(\beta_{1}\right)$, apresentaram o sinal esperado para a hipótese de existência da característica qualitativa. No entanto, $\beta_{3}$ é significante ao nível de $10 \%$ para o Lucro Operacional, confirmando a hipótese de Basu (1997): o reconhecimento das más notícias é feito de forma mais intensa em comparação com as boas notícias.

Cabe destacar a diferença encontrada para os valores de $\beta_{3}$ para o Lucro Operacional e Lucro Líquido (0,26 - 0,03). Uma explicação possível para essa informação é que as Companhias são mais conservadoras no reconhecimento de más notícias quando elas estão ligadas as suas atividades operacionais, uma vez que esses itens são mais recorrentes que os itens não operacionais e, por isso, são utilizadas para avaliações sobre retorno dos investimentos de formas criteriosas e mais passíveis de comparações.

A expressiva diferença encontrada entre os parâmetros do Lucro Líquido e do Lucro Operacional dá a entender que a prática de conservadorismo se daria de forma mais intensa em itens operacionais como provisão de devedores duvidosos, provisão para obsolescência de estoque, depreciação, amortização e exaustão, provisões de $13^{\circ}$ salário, provisão de férias, provisão para contingências cíveis, trabalhistas, tributárias. Por outro lado, as empresas não apresentariam os mesmos critérios para accruals não operacionais decorrentes de transações não incluídas nas atividades principais ou acessórias que constituam objeto da empresa, como o exemplo das doações e subvenções em entidades que dependem dessas doações para a consecução de suas atividades institucionais.

O coeficiente $\beta_{2}$ reflete o reconhecimento direto entre Retorno Econômico e Lucro, apresenta sinal positivo, como esperado pelo modelo. O parâmetro varia de 0,01 (Lucro Líquido) para 0,03 (Lucro Operacional), demonstrando que há maior reconhecimento do conservadorismo na lucratividade do que na rentabilidade.

O fato possibilita inferir que a expectativa gerada a partir da capacidade operacional da empresa é avaliada de forma mais confiável pelo investidor, uma vez que há maior utilização de conservadorismo condicional no reconhecimento nos itens operacionais. A informação sobre a lucratividade é de melhor qualidade informacional em comparação com a informação de rentabilidade porque possui menos expectativa de se realizar. A significância do parâmetro para Lucro Líquido está fora do intervalo de confiança, mesmo o parâmetro sendo confiável ao nível de 1\% para o Lucro Operacional.

As regressões estimadas apresentaram baixo coeficiente de determinação ajustado ( $\mathrm{R}^{2}$ ajustado) em comparação com o estudo de Basu, o qual em 1997 aproximou-se de $10 \%$. $\mathrm{O} \mathrm{R}^{2}$ mede a qualidade do ajustamento da equação de regressão, mostrando, percentualmente, a variação total do Lucro que é explicada pelo Retorno Econômico. $\mathrm{O}$ valor encontrado conota uma baixa correlação entre o Retorno Econômico e o Lucro das empresas amostrais. Acredita-se que um dos motivos causadores é a característica do mercado brasileiro, que, segundo Perobelli e Ness (2000), no qual os dados contábeis têm menor impacto nas decisões de investidores quando comparadas ao mercado americano.

Faz-se necessário lembrar que o tamanho da amostra é pequeno para inferências mais consistentes, uma vez que a teoria de dados em painel é elaborada para $\mathrm{T}$ pequeno e $\mathrm{N} \rightarrow \infty$. No entanto, essa é uma limitação para as pesquisas empíricas realizadas no mercado brasileiro, pois existiam cerca de 550 companhias listadas na Bovespa em novembro de 2009. 


\subsubsection{Análise do conservadorismo nas companhias e a relação com a governança corporativa}

Com o objetivo de avaliar se existe alguma relação entre o nível de utilização do conservadorismo e pertencer a algum dos níveis de governança da Bovespa, as 96 companhias foram segmentadas em dois grupos: (1) o primeiro grupo com 58 companhias listadas em algum dos níveis de governança; (2) o segundo grupo com 38 companhias que fazem parte do mercado tradicional, portanto, que não aderiram aos níveis de governança da Bovespa. Inicialmente, testou-se estimar o modelo original com a inclusão de uma variável dummy que possibilitasse diferenciar as companhias, porém a regressão estimada pela abordagem de efeito fixo remove as variáveis constantes ao longo do tempo para todas as observações. A opção passou a ser estimar regressões diferentes para os dois subgrupos.
Os resultados encontrados podem ser visualizados na Tabela $3 \mathbf{0}$ e na Tabela $4 \mathbf{0}$.

As regressões apresentaram autocorrelação dos resíduos e foram novamente estimadas utilizando Mínimos Quadrados Generalizados com distúrbios correlacionados considerando como forma de correlação Panel-specific AR (1) e autocorrelação dos resíduos como método de computação do software.

As observações encontradas mostram que as companhias do primeiro grupo demonstraram que suas políticas contábeis de mensuração apresentam conservadorismo condicional para itens operacionais e não operacionais, dado que o coeficiente $\beta_{3}$ se mostrou significativo. Em termos comparativos, as empresas que participam dos níveis da Bovespa possuem coeficiente $\beta_{3}$ maiores do que as que não participam, isto é, um maior grau de conservadorismo.

Tabela 3 Resultado da regressão reversa de lucros para empresas do primeiro subgrupo da amostra

\begin{tabular}{l|c|c|c|c|c|c}
\hline \multirow{2}{*}{ Coeficientes } & \multicolumn{3}{|c|}{ Lucro Líquido } & \multicolumn{3}{c}{ Lucro Operacional } \\
\cline { 2 - 7 } & Valor & Teste $\mathrm{z}$ & Prob. & Valor & Teste z & Prob. \\
\hline$\beta_{0}$ & $0,12^{*}$ & $11,12^{*}$ & $0,00^{*}$ & $0,17^{*}$ & $11,61^{*}$ & $0,00^{*}$ \\
\hline$\beta_{1}$ & $-0,03^{*}$ & $-1,19^{*}$ & $0,235^{*}$ & $-0,03^{*}$ & $-0,86^{*}$ & $0,39^{*}$ \\
\hline$\beta_{2}$ & $0,02^{*}$ & $2,34^{*}$ & $0,02^{*}$ & $0,03^{*}$ & $2,22^{*}$ & $0,03^{*}$ \\
\hline$\beta_{3}$ & $0,18^{*}$ & $1,63^{*}$ & $0,10^{*}$ & $0,30^{*}$ & $2,02^{*}$ & $0,04^{*}$ \\
\hline $\mathrm{N}$ & \multicolumn{3}{|c}{58} & & 58 & \\
\hline $\mathrm{T}$ & \multicolumn{3}{|c}{3} & & 3 \\
\hline
\end{tabular}

* Valores reestimados pelo MQG do software estatístico Stata ${ }^{\circledR}$

Tabela 4 Resultado da regressão reversa de lucros para empresas do segundo subgrupo da amostra

\begin{tabular}{|c|c|c|c|c|c|c|}
\hline \multirow{2}{*}{ Coeficientes } & \multicolumn{3}{|c|}{ Lucro Líquido } & \multicolumn{3}{|c|}{ Lucro Operacional } \\
\hline & Valor & Teste $z$ & Prob. & Valor & Teste $z$ & Prob. \\
\hline$\beta_{0}$ & $0,10^{*}$ & $3,94^{*}$ & $0,00^{*}$ & $0,10^{*}$ & 3,15 & 0,00 \\
\hline$\beta_{1}$ & $0,00^{*}$ & $-0,03^{*}$ & $0,98^{*}$ & $-0,01^{*}$ & $-0,07$ & 0,948 \\
\hline$\beta_{2}$ & $-0,03 *$ & $-1,01^{*}$ & $0,31^{*}$ & $0,05^{*}$ & 1,75 & 0,08 \\
\hline$\beta_{3}$ & $0,24^{*}$ & $0,86^{*}$ & $0,39^{*}$ & $0,20^{*}$ & 0,56 & 0,57 \\
\hline $\mathrm{N}$ & \multicolumn{3}{|c|}{38} & \multicolumn{3}{|c|}{38} \\
\hline $\mathrm{T}$ & \multicolumn{3}{|c|}{3} & \multicolumn{3}{|c|}{3} \\
\hline
\end{tabular}

\footnotetext{
* Valores reestimados pelo MQG do software estatístico Stata ${ }^{\circledR}$
} 
Por outro lado, o conservadorismo nas companhias do segundo subgrupo nem pode ser confirmado, pois apesar de os coeficientes $\beta_{1}$ e $\beta_{3}$ apresentarem os sinais esperados, não foram significativos estatisticamente.

Um dos objetivos dos níveis de governança da Bovespa é criar mecanismos e regras para as companhias no intuito de reduzir o risco associado a investimento em tais companhias, por meio da proteção implícita aos acionistas. Entre as regras a serem seguidas por essas companhias incluem maior quantidade e melhoria nas informações prestadas na expectativa de reduzir a assimetria informacional entre os diferentes tipos de usuários.

Esses mecanismos e regras estão intimamente relacionados à teoria de contratos, o que deixa essas empresas mais expostas a averiguações por parte dos investidores quanto a ações oportunistas dos agentes, o que aumenta o risco dos agentes em publicar desempenhos e resultados que não se susteriam no futuro e poderiam ser negativos para sua imagem e para a imagem da empresa com os investidores.

\subsection{Análise empírica a partir do Modelo de Kahn e Watts (2009)}

$\mathrm{Na}$ Tabela $5 \theta$, apresentam-se os resultados das médias dos coeficientes para regressões estatísticas, conforme o modelo de Kahn e Watts (2009) para a análise do Conservadorismo na mensuração contábil. Os efeitos do Conservadorismo foram examinados em dois diferentes conceitos de lucro: Lucro Líquido e Lucro Operacional. Na estimação das cross-sections, não foram encontrados problemas de autocorrelação e heterocedasticidade.

Dos resultados obtidos para as boas notícias (G_Score), todas as variáceis apresentaram sinais conforme o previsto, com exceção do Retorno Econômico (RE), apontando para um reconhecimento de boas notícias de forma oportuna, o que não é esperado para companhias conservadoras. No entanto, nenhuma das variáveis G_Score se mostraram significativas, não possibilitando maiores in- ferências a respeito das variáveis Tam, MB e Alav para boas notícias.

As variáveis encontradas para as más notícias (C_Score) apresentaram sinais conforme a previsão, no entanto, apenas a variável que multiplica a Dummy, o Retorno Econômico e o Tamanho (D x RE x Tam) foi significativa ao nível de $10 \%$. O resultado é consistente com a presunção de Kahn e Watts (2009) que as empresas maiores apresentam menor grau de oportunidade assimétrica.

A variável (D x RE x Tam) apresentou resultado mais expressivo para o Lucro Operacional, confirmando os resultados obtidos pelo modelo de Basu, no sentido de que a expectativa gerada a partir da capacidade operacional da empresa é avaliada de forma mais confiável pelo investidor e consequentemente apresenta maior Conservadorismo.

As regressões foram estimadas com a inclusão da variável Governança, uma variável binária que apresenta resultado 1 , caso a empresa pertença a um dos níveis de governança da Bovespa, e 0, caso não pertença. A ideia era de analisar qual o impacto das obrigações impostas às empresas que aderiram aos níveis com uma maior utilização de conservadorismo. Porém a variável apresentou valor igual a zero tanto para o Lucro Líquido como para o Lucro Operacional, e não apresentaram significância estatística.

A partir desse modelo, não foi possível fazer inferências a respeito de que as empresas listadas nos níveis de governança são levadas a adotar práticas mais conservadoras, deixando ainda em aberto essa questão para novas pesquisas.

As estimativas obtidas para o grupo de variáveis formada pelo tamanho, alavancagem e market-to-book, além das variáveis dummies de coeficiente angular para cada uma delas, não foram significativas. O modelo de Kahn e Watts (2009) supõe associação positiva entre a variável dependente e as variáveis de alavancagem e market-to-book e de associação negativa com a variável tamanho, o que condiz com o resultado encontrado. O intercepto e a variável Dummy não foram significativos. 
Tabela 5 Coeficientes médios das regressões estimadas

\begin{tabular}{|c|c|c|c|c|c|}
\hline \multirow{2}{*}{ V. Independentes } & \multirow{2}{*}{ Prev. sinal } & \multicolumn{2}{|c|}{ Lucro Líquido } & \multicolumn{2}{|c|}{ Lucro Operacional } \\
\hline & & Coeficiente & t-stat. & Coeficiente & t-stat \\
\hline Intercepto & & $-0,15$ & $-0,43$ & $-0,02$ & $-0,06$ \\
\hline $\mathrm{D}$ & & 0,19 & 1,02 & 0,12 & 0,70 \\
\hline \multicolumn{6}{|l|}{ G_Score } \\
\hline RE & + & $-0,12$ & $-0,17$ & $-0,50$ & $-1,56$ \\
\hline RE $\times$ Tam & + & 0,01 & 0,22 & 0,04 & 1,67 \\
\hline$R E \times M B$ & - & $-0,01$ & $-0,82$ & $-0,02$ & $-0,73$ \\
\hline RE x Alav & - & 0,00 & $-0,09$ & 0,00 & $-0,10$ \\
\hline \multicolumn{6}{|l|}{ C_Score } \\
\hline $\mathrm{D} \times \mathrm{RE}$ & + & 0,69 & 0,85 & 1,10 & 0,80 \\
\hline $\mathrm{D} \times \mathrm{RE} \times \mathrm{Tam}$ & - & $-0,09$ & $-5,26^{*}$ & $-0,12$ & $-1,92^{*}$ \\
\hline $\mathrm{D} \times \mathrm{RE} \times \mathrm{MB}$ & + & 0,12 & 0,63 & 0,14 & 0,68 \\
\hline $\mathrm{D} \times \mathrm{RE} \times$ Alav & + & 0,47 & 1,02 & 0,43 & 0,66 \\
\hline Tam & & 0,02 & 0,82 & 0,01 & 0,61 \\
\hline $\mathrm{MB}$ & & 0,00 & $-0,32$ & 0,00 & $-0,22$ \\
\hline Alav & & 0,00 & 0,18 & 0,00 & 0,32 \\
\hline $\mathrm{D} \times \mathrm{Tam}$ & & $-0,02$ & $-1,17$ & $-0,01$ & $-0,70$ \\
\hline $\mathrm{D} \times \mathrm{MB}$ & & 0,02 & 0,40 & 0,00 & $-0,28$ \\
\hline D x Alav & & 0,08 & 1,66 & 0,02 & 0,15 \\
\hline
\end{tabular}

\begin{tabular}{c|c|c|c|c|c}
\hline Governança & & 0,00 & $-0,39$ & 0,00 & $-0,06$ \\
\hline
\end{tabular}

* Significativo ao nível $10 \%$

\section{CONCLUSÕES}

A Contabilidade tem fundamental importância na influência do valor de mercado das companhias. Os resultados evidenciados levam informações aos investidores, que reagem conforme as expectativas geradas pelo resultado reportado. O lucro contém informações sobre o futuro da companhia, por esse motivo deve-se resguardar a participação de cada grupo financiador nos fluxos de caixa gerados para o momento de sua realização.

Considerando que a Contabilidade atua em um ambiente de mensuração que exige estimativas de valores futuros e incertos, próprios da aplicação do Regime de Competência. O Conservadorismo consiste na inclusão de certa dose de cautela na formulação dos julgamentos necessários na elaboração de es- timativas nessas condições de incertezas, por isso é um atributo de qualidade informacional das demonstrações contábeis.

Os resultados obtidos pelo modelo reverso de lucros associados a retornos confirmam o reconhecimento direto entre Retorno Econômico e Lucro, medido pelo coeficiente $\beta_{2}$, ao mesmo tempo em que os resultados negativos são reconhecidos de forma mais oportuna, conforme parâmetro estimado $\beta_{3}$. Além disso, o modelo mostra diferenciação positiva quanto à utilização de conservadorismo para as empresas que aderiram aos níveis de governança.

Os valores estimados pelo modelo de Kahn e Watts (2009), com exceção do retorno econômico, apresentam correlação esperada 
entre a variável dependente e as variáveis independentes, porém não foi encontrada significância estatística que possibilite confirmar as relações conservadoras entre market-to-book, alavancagem e suas interações com boas e más notícias com os lucros reportados pelas companhias. Por outro lado, o resultado obtido para a interação da má notícia com o tamanho da empresa foi consistente com o previsto e mostrou significância estatística. Esse fato confirma a ideia que maiores empresas apresentam menor grau de oportunidade assimétrica, ou seja, são menos conservadoras que as empresas menores.

Outro importante fato observado nos dois modelos é a diferença existente entre o grau de conservadorismo utilizado para o Lucro Operacional e o Lucro Líquido. As práticas contábeis utilizadas para os itens operacionais são mais conservadoras em relação às práticas utilizadas para itens não operacionais, o que pode ser entendido no sentido que a expectativa gerada a partir da capacidade operacional da empresa é avaliada de forma mais confiável pelo investidor.

Ao utilizar variáveis econômicas, criam-se vantagens quando as más notícias não podem ser tão claramente visíveis nas Demonstrações Contábeis, mas que acabam por diminuir os resultados futuros esperados. Como exemplo, um fato negativo pode estar influenciando o resultado atual e possivelmente o resultado futuro, porém os gestores não conseguem captar a sinalização da má notícia de forma tão rápida quanto o mercado.

Por outro lado, o conservadorismo condicional pode estar sendo confundido com outras variáveis de natureza econômica, não incluídas no modelo e que podem influenciar nos preços das ações. Por exemplo, as empre- sas podem estar passando por um período de queda produtiva dentro da normalidade esperada, porém os gestores não reportariam oportunamente toda a perda no resultado. $\mathrm{O}$ mercado pode reconhecer a má notícia e diminuir o preço da ação em um sentido correlato com diminuição dos lucros, mesmo sem a mensuração das perdas de forma esperada no ambiente conservador.

$\mathrm{Na}$ situação de assimetria de informação, investidores com informações privilegiadas podem influenciar a movimentação de mercado e forçar alterações de preço das ações sem que isso tenha relação com a mensuração de boas ou más notícias. O movimento de preços estaria relacionado à especulação, ou seja, os agentes do mercado financeiro por vezes, agem de forma independente, baseados em expectativas próprias (decisões ad hoc) em que o resultado sobre o retorno da ação não esteja diretamente relacionado às boas ou más notícias.

Os resultados reforçam recomendações sobre novas pesquisas em relação a avaliar a qualidade informacional dos resultados publicados por empresas brasileiras; entre as sugestões apresentam-se: (a) Replicar a metodologia comparando os resultados obtidos com as mudanças introduzidas pela Lei 11.638/07 no reconhecimento e mensuração contábil de alguns itens econômicos; (b) Analisar a qualidade da informação contábil a partir de outros atributos além de conservadorismo; (c) Análisar da influência de impostos e outros itens não operacionais na qualidade das informações contábeis e no gerenciamento de resultados e (d) Buscar desenvolver modelos estatísticos mais robustos para a avaliação de conservadorismo condicional aplicado à realidade brasileira.

\section{Referências}

AAA. American Accounting Association. A Statement of basic accounting theory ASOBAT. Florida: American Accounting Association, 1966.

ALMEIDA, J. C. G.; SCALZER, R. S.; COSTA, F.

M. Níveis de governança corporativa e grau de conservadorismo: estudo empírico em companhias abertas listadas na Bovespa. Revista de Contabilidade e Organizações, v. 2, n. 2, p. 117-130, jan./abr. 2008. ANTHONY, R. N. Contabilidade gerencial. São Paulo: Atlas, 1972. 
ANTUNES, M. A.; PROCIANOY, J. L. Os efeitos das decisões de investimento das firmas sobre os preços de suas ações no mercado de capitais. Revista de Administração, São Paulo, v. 38, n. 1, p. 5-14, jan./fev./ mar. 2003.

ASSAF NETO, A. Finanças corporativas e valor. 3. ed. São Paulo: Atlas, 2008.

BALL, R. J.; BROWN, P. An empirical evaluation of accounting income numbers. Journal of Accounting Research, Chicago, v. 6, p. 159-178, Autumn 1968. ; SHIVAKUMAR, L. Earnings quality in UK private firms: comparative loss recognition timeliness. Journal of Accounting and Economics, Amsterdam, v. 39, p. 83-128, 2005.

BASU, S. The conservatism principle and the asymmetric timeliness of earnings. Journal of Accounting and Economics, Amsterdam, v. 24, n. 1, p. 3-37, 1997. BEAVER; W. H. The information content of earnings. Journal of Accounting Research, Chicago, v. 6, p. 67-92, 1968.

; RYAN, S. G. Biases and lags in book value and their effects on the ability of the book-to-market ratio to predict book return on equity. Journal of Accounting Research, v. 38, n. 1, p. 127-148, 2000.

BRASIL. COMITÊ DE PRONUNCIAMENTOS CONTÁBEIS. Pronunciamento conceitual básico. Estrutura conceitual para a elaboraçã̃o e apresentação das demonstrações contábeis. Correlação às Normas Internacionais de Contabilidade. Estrutura para a Preparação e a Apresentação das Demonstrações Contábeis. Disponível em: <www.cpc.gov.br $>$. Acesso em: 10 abr. 2008.

CAMPBELL, J.; LO, A.; MACKINLAY, C. The econometrics of financial markets. Princeton University Press, Princeton, NJ, 1997.

COCHRANE, J. Asset Pricing, NJ: Princeton University Press, 2001.

COELHO, A. C. D. Qualidade informacional e conservadorismo nos resultados contábeis publicados no Brasil. 2007. 240 f. Tese (Doutorado em Contabilidade e Controladoria) - Pós-graduação em Contabilidade e Controladoria, Faculdade de Economia, Administração e Contabilidade, Universidade de São Paulo, São Paulo, 2007.

\section{; LIMA, I. S. Qualidade informacional e}

conservadorismo nos resultados contábeis publicados no Brasil. Revista Contabilidade e Finanças, USP, São Paulo, v. 18 , n. 45 , p. $38-49$, set./dez. 2007.

COSTA, F. M.; COSTA, A. C. O.; LOPES; A. B.

Conservadorismo em cinco países da América do sul.

Revista Contabilidade e Finanças, USP, São Paulo, n. 41, p. 7-20, maio/ago. 2006.

DIAS FILHO, J. M. A Linguagem utilizada

na evidenciação contábil: uma análise de sua compreensibilidade à luz da teoria da comunicação. Caderno de Estudos, São Paulo, FIPECAFI, v. 13, n. 24, p. 38-49, jul./dez. 2000.

EASLEY, D.; HVIDKJAER, S.; O'HARA, M. Is information risk a determinant of asset returns? The Journal of Finance, v. 57, n. 5, p. 2185-2221, oct. 2002.
FAMA, E. F. Efficient capital markets: a review of theory and empirical work. The Journal of Finance, Cambridge, v. 25, p. $383-417,1970$.

; MACBETH, J. D. Risk, return and equilibrium: empirical tests. Journal of Political Economy, v. 81, n. 3, p. 607-636, maio/jun. 1973.

FELTHAM, G. M.; OHLSON, J. Uncertainty resolution and the theory of depreciation measurement. Journal of Accounting Research, v. 34, n. 2, p. 209-234, 1996. GARCÍA-LARA, J. M.; MORA, A. Balance sheet versus earnings conservantism. Europe. Europen Accounting Review, London, v. 13, n. 2, p. 261-292, 2004.

GESEL - Grupo de Estudos do Setor Elétrico do Insituto de Economia da UFRJ. Séries econômico-financeiras das empresas do setor de energia elétrica. Rio de Janeiro: Synergia: GESEL, UFRJ, 2006.

Séries econômico-financeiras das empresas do. setor de energia elétrica. Rio de Janeiro: Synergia: GESEL, UFRJ, 2007.

GIVOLY, D.; HAYN, C. The changing time-series properties of earnings, cash flows and accruals: has financial reporting become more conservative? Journal of Accounting and Economics, n. 29, p. 287-320, ago. 2000. GONZAGA, R. P.; COSTA, F. M. A relação entre conservadorismo contábil e os conflitos entre acionistas controladores e minoritários sobre as políticas de dividendos nas empresas brasileiras listadas na Bovespa. Revista Contabilidade e Finanças, USP, São Paulo, v. 20, n. 50, p. 95-109, maio/ago. 2009.

GUJARATI, D. Econometria básica. Rio de Janeiro: Elsevier, 2006.

HENDRIKSEN, E. S.; BREDA, M. F. Van. Teoria da Contabilidade. 5. ed. São Paulo: Atlas, 1999.

HSIAO, C. Analysis of panel data. Cambridge: Cambridge University Press, 1986.

IASB. International Accounting Standards Board. Estrutura conceitual para a elaboração e apresentação das demonstrações contábeis. Normas Internacionais de Contabilidade. São Paulo: IBRACON, 2001.

JAEDICKE, R. K.; SPROUSE, R. T. Fluxos contábeis: renda, fundos e capital. Trad. José Bonifácio da Cruz; revisão e adaptações técnicas do Prof. Celso Albano Costa. São Paulo: Atlas, 1972.

KAM, V. Accounting theory. 2. ed. Califórnia: John Wiley \& Sons, 1986.

KHAN, M.; WATTS, R. L. Estimation and empirical properties of a firm-year measure of accounting conservatism. Journal of Accounting and Economics, v. 48, p. $132-150 ; 2009$.

KOTHARI, S. P. Capital markets research in accounting. Journal of Accounting and Economics, v. 31, p. 105-231, 2001.

LIMA, M. R.; BRITO, R. D. O que determina e estrutura de capital no Brasil. Disponível em: <http:// virtualbib.fgv.br/ocs/index.php/ebf/3EBF/paper/ viewFile/1607/718>. Acesso em: 18 set. 2010 . LOPES, A. B. A relevância da informação contábil para o mercado de capitais: O modelo de Ohlson aplicado à BOVESPA. 2001. Tese (Doutorádo em Ciências Contábeis) - Programa de Pós-Graduação em 
Controladoria e Contabilidade, Faculdade de Economia, Administração e Contabilidade, Universidade de São Paulo, São Paulo, 2001.

MADDALA, G. S. Introdução à econometria. 3. ed. Rio de Janeiro: LTC, 2003.

MAROCO, J. Análise estatística: com utilização do SPSS. 2. ed. Lisboa: Silabo, 2003.

OHLSON, J. Earnings, book values, and dividends in equity valuation: an empirical perspective. Contemporary Accounting Research, v. 18, p. 107-120, 2001.

PENMAN, S. H.; ZHANG, X. J. Accounting. conservantism, the quality of earnings, and stock options. The Accounting Review, v. 77, n. 2, p. 237-264, apr. 2002.

PEROBELLI, F. F. C.; PEROBELLI, F. S.; ARBEX, M. A. Expectativas racionais e eficiência informacional: análise do mercado acionário brasileiro no período 1997-1999. Revista Administração Contemporânea, Curịtiba, v. 4, n. 2, maio/ago. 2000.

; NESS, W. L. Reações do mercado acionário a variações inesperadas nos lucros das empresas: um estudo sobre a eficiência informacional no mercado brasileiro. In: ENANPAD 2000. Anais..., Florianópolis, 2000.
RANGEL, L. L.; TEIXEIRA, A. J. C. O conservadorismo contábil e o valor de mercado. In: ENANPAD, 18., 2003, Atibaia. Anais... Atibaia, 2003.

SANTOS, L. S. R. S.; COSTA, F. M. Conservadorismo contábil e timeliness: evidências empíricas nas demonstrações contábeis em empresas brasileiras com ADRs negociadas na Bolsa de Nova Iorque. Revista Contabilidade e Finanças, USP, São Paulo, v. 19, n. 48, p. 27-36, set./dez. 2008.

SHANNON, C. E.; WEAVER, W. The matematical theory of communication. London: University of Illinois, 1963. $125 \mathrm{p}$.

SILVA, O. M.; CRUZ JR., J. C. Dados em painel: uma análise do modelo estatístico. In: SANTOS, M. L.; VIEIRA, W. C. (Org.). Métodos quantitativos em economia. Viçosa, MG: Imprensa Universitária, 2004. TAKAMATSU, R. T.; LAMOUNIER, W. M.; COLAUTO, R. D. Impactos da divulgação de prejuízos nos retornos de ações de companhias participantes do Ibovespa.

Revista Universo Contábil, Blumenau, v. 4, n. 1, p. 46-63, jan./mar. 2008.

WATTS, R. Conservatism in accounting part I: explanations and implications. Accounting Horizons, $\mathrm{n}$. 17, v. 3, p. 207-221, sep. 2003. 